\title{
Pathophysiological Characteristics of Non-Alcoholic Steatohepatitis- Like Changes in Cholesterol-Loaded Type 2 Diabetic Rats
}

\author{
Y. TORINIWA ${ }^{1,3}$, M. MURAMATSU ${ }^{1}$, Y. ISHII ${ }^{1}$, E. RIYA ${ }^{2}$, K. MIYAJIMA ${ }^{2}$, S. OHSHIDA ${ }^{2}$, \\ K. KITATANI ${ }^{4}$, S. TAKEKOSHI ${ }^{4}$, T. MATSUI ${ }^{5}$, S. KUME $^{5}$, T. YAMADA ${ }^{3}$, T. OHTA ${ }^{1}$ \\ ${ }^{1}$ Japan Tobacco Inc., Central Pharmaceutical Research Institute, Murasaki-cho, Takatsuki, Osaka, \\ Japan, ${ }^{2}$ Japan Tobacco Inc., Central Pharmaceutical Research Institute, Toxicology Research \\ Laboratories, Naganuki, Hadano, Kanagawa, Japan, ${ }^{3}$ Department of Agrobiology, Faculty of \\ Agriculture, Niigata University, Nishi-ku, Niigata, Japan, ${ }^{4}$ Department of Cell Biology, Division of \\ Host Defense Mechanism, Tokai University School of Medicine, Shimokasuya, Isehara, Kanagawa, \\ Japan, ${ }^{5}$ Kyoto University, Graduate School of Agriculture, Kitashirakawa, Sakyo-ku, Kyoto, Japan
}

Received October 20, 2017

Accepted February 19, 2018

On-line May 10, 2018

\begin{abstract}
Summary
Spontaneously Diabetic Torii (SDT) fatty rats, a new obese diabetic model, reportedly presented with features of non-alcoholic steatohepatitis (NASH) after 32 weeks of age. We tried to accelerate the onset of NASH in SDT fatty rats using dietary cholesterol loading and noticed changes in the blood choline level which is expected to be a NASH biomarker. Body weight and biochemical parameters were measured from 8 to 24 weeks of age. At 16, 20, 24 weeks, pathophysiological analysis of the livers were performed. Hepatic lipids, lipid peroxides, and the expression of mRNA related to triglyceride (TG) synthesis, inflammation, and fibrosis were evaluated at 24 weeks. Hepatic fibrosis was observed in SDT fatty rats fed cholesterol-enriched diets (SDT fatty-Cho) from 16 weeks. Furthermore, hepatic lipids and lipid peroxide were significantly higher in SDT fatty-Cho than SDT fatty rats fed normal diets at 24 weeks. Hepatic mRNA expression related to TG secretion decreased in SDT fatty-Cho, and the mRNA expression related to inflammation and fibrosis increased in SDT fatty-Cho at 24 weeks. Furthermore, SDT fatty-Cho presented with increased plasma choline, similar to human NASH. There were no significant changes in the effects of feeding a cholesterol-enriched diet in Sprague-Dawley rats. SDT fatty-Cho has the potential to become a valuable animal model for NASH associated with type 2 diabetes and obesity.
\end{abstract}

\section{Key words}

Dietary cholesterol feeding • Fatty liver • NASH • Plasma choline concentration $\bullet$ SDT fatty rat

\section{Corresponding author}

T. Ohta, Biological/Pharmacological Research Laboratories, Central Pharmaceutical Research Institute, Japan Tobacco Inc., 1-1 Murasaki-cho, Takatsuki, Osaka 569-1125, Japan. E-mail: takeshi.ota@jt.com

\section{Introduction}

Non-alcoholic fatty liver disease (NAFLD) is associated with obesity, dyslipidemia, hypertension, type 2 diabetes and insulin resistance (de Alwis and Day 2008). NAFLD refers to the pathology of fatty livers ranging from simple steatosis through non-alcoholic steatohepatitis (NASH) to cirrhosis (Greenfield et al. 2008). Some of NAFLD cases lead to hepatocellular carcinoma (Malik et al. 2009, Ertle et al. 2011, Hucke et al. 2011, Yang et al. 2012). The pathogenesis of NASH seems to be poorly defined, and effective pharmacological therapies have not been approved all over the world.

To understand the difficult features of NAFLD/NASH, animal models offer important information. $o b / o b$ mice and $d b / d b$ mice have been reported as NAFLD animal models, spontaneously exhibiting hepatic steatosis based on insulin resistance and obesity but not progressing to liver fibrosis when fed normal diets (Diehl 2005, Ge et al. 2010, Xu et al. 2012). On the other hand, choline deficient (CD) diet-induced 
NASH presents with hepatic steatosis, inflammation and fibrosis in F344 rats (Kawaratani et al. 2008, Tsujimoto et al. 2008, Tsujimoto et al. 2009). However, CD diet-fed animals do not present with obesity, type 2 diabetes, hyperlipidemia, and insulin resistance. So, the pathophysiology of NASH induced by $\mathrm{CD}$ diets is different from human NASH.

Spontaneously Diabetic Torii Lepr $^{f a}$ (SDT fatty) rats, established by transferring the allele of the Zucker fatty rat into the SDT rat genome, denote a new model for obese type 2 diabetes (Masuyama et al. 2005, Katsuda et al. 2014). There is a gender difference in the degree of insulin resistance, and female SDT fatty rats show higher blood insulin levels than male SDT fatty rats for a long period (Ohta et al. 2014). Histopathological observations revealed NASH features at 32-40 weeks of age in female SDT fatty rat livers (Ishii et al. 2015). On the other hand, male SDT fatty rats did not show NASH-like lesions in our preliminary study. Female SDT fatty rats may be useful for NASH research. However, a long period of time is required prior to the onset of NASH. There are some reports that show the relationship between NASH and dietary cholesterol (Tous et al. 2006, Wouters et al. 2008). In diet-induced obese mice or rats, steatohepatitis was significantly induced, especially in cholesterolenriched diets group (Mari et al. 2006). In this study, for the purpose of improving the usefulness of female SDT fatty rats as a NASH animal model, we investigated the histological features of livers in female SDT fatty rats fed cholesterol-enriched chow and compared these animals with female SDT fatty rats fed normal chow. In addition to the pathological analysis, biochemical parameters, hepatic lipid content and the expression of genes related with lipid metabolism, inflammation, and fibrosis, were evaluated.

Furthermore, we investigated plasma choline concentrations in female SDT fatty rats. In human NASH patients, plasma choline concentrations are elevated (Imajo et al. 2012, Imajo et al. 2014). Plasma choline concentrations may be useful non-invasive biomarkers for NASH. We tried to investigate plasma choline concentrations to check the change in SDT fatty rats fed cholesterol-enriched chow.

\section{Materials and Methods}

\section{Animals}

This experiment was conducted in compliance with the Guidelines for Animal Experimentation in Japan Tobacco Biological/Pharmacological Research
Laboratories. The animal protocol was designed to minimize pain or discomfort to the animals. Female SDT fatty rats were purchased from CLEA Japan (Tokyo, Japan), and age-matched female Sprague-Dawley (SD) rats (CLEA Japan, Tokyo, Japan) were used as control animals for SDT fatty rats. The rats were housed individually in suspended bracket cages in a climatecontrolled room at a temperature of $23 \pm 3{ }^{\circ} \mathrm{C}$, humidity $55 \pm 15 \%$, and a $12 \mathrm{~h}$ dark-light cycle, and had free access to diets (normal chow CRF-1 or CRF-1 added $2 \%$ cholesterol, Oriental Yeast Co., Ltd., Tokyo, Japan) and water. At 4 weeks of age, all animals were started feeding with normal chow or cholesterol-enriched diets. All animals were sacrificed by exsanguination under light isoflurane anesthesia. At 16 weeks of age, 5 SDT fatty rats fed $2 \%$ cholesterol (SDT fatty-Cho) were sacrificed. 6 SDT fatty-Cho were sacrificed at 20 and 24 weeks of age, respectively. At 24 weeks of age, 5 SDT fatty rats fed normal chow (SDT fatty-NC), $5 \mathrm{SD}$ rats fed $2 \%$ cholesterol (SD-Cho), and $5 \mathrm{SD}$ rats fed normal chow (SD-NC), were sacrificed, respectively.

\section{Body weight and biochemical analysis}

Body weight and biochemical parameters, such as plasma glucose, triglyceride (TG), total cholesterol (TC) levels, alanine aminotransferase (ALT), aspartate aminotransferase (AST) activities and insulin levels were measured at 8, 12, 16, 20, 24 weeks of age. Blood samples were collected from the tail veins of rats. Plasma glucose, TG, TC levels, and ALT, AST activities were measured by using commercial kits (Roche Diagnostics, Basel, Switzerland) in an automatic analyzer (Hitachi 7170S; Hitachi, Tokyo, Japan) and plasma insulin concentrations were measured by commercial ELISA kits (Rat Insulin ELISA Kit; Morinaga Institute of Biological Science, Yokohama, Japan) as biochemical parameters. Plasma choline concentrations were analyzed using high performance liquid chromatography (HPLC) at Skylight Biotech (Akita, Japan). At 10, 16, 24 weeks of age, 6 SDT fatty-Cho and 5 SDT fatty-NC were tested for plasma choline. At 24 weeks of age, $5 \mathrm{SD}-\mathrm{Cho}$, and 5 SD-NC, were tested for plasma choline.

\section{Hepatic lipid content}

Liver portions which collected from 24 weeks of age animals were used for this assay. A portion of the livers weighing approximately $100 \mathrm{mg}, 0.5 \mathrm{ml}$ of methanol, and Zirconia beads were added to tubes. The liver portions were homogenized using a Tissue Lyser 2 (QIAGEN, Tokyo, Japan) at $25 \mathrm{~Hz}$ for $2 \mathrm{~min}$. A $1 \mathrm{ml}$ 
volume of chloroform was added to the homogenized solution and mixed thoroughly. The mixture was then centrifuged $\left(16,000 \mathrm{~g}\right.$ for $5 \mathrm{~min}$ at $\left.4{ }^{\circ} \mathrm{C}\right)$ and the resulting supernatant collected. Solvents contained in the $0.5 \mathrm{ml}$ of supernatant were dried under a stream of nitrogen gas. A $0.5 \mathrm{ml}$ volume of 2-propanol was added to the residue, which was subsequently dissolved again. To measure free cholesterol (FC), the residue was redissolved in $0.2 \mathrm{ml}$ of 2-propanol containing $10 \%$ Triton X-100. The TG and TC concentrations in the 2-propanol solution were determined using a biochemistry automatic analyzer. FC and Free fatty acid (FFA) concentrations were analyzed using Free-cholesterol-E kits or NEFA-C kits (Wako Pure Chemical Industries, Ltd., Osaka, Japan).

To measure diacylglycerol (DAG), the solvents contained in the $1.5 \mathrm{ml}$ of supernatant were dried under a stream of nitrogen gas. A $750 \mu \mathrm{l}$ volume of $100 \mathrm{mmol} / \mathrm{l}$ TRIS-HCl (pH 7.4) containing $250 \mathrm{mmol} / \mathrm{l}$ sucrose and $1 \%$ Triton $\mathrm{X}$ was added to the residue and mixed thoroughly. A $750 \mu \mathrm{l}$ volume of ethyl acetate was added to the liquid and mixed thoroughly. The mixture was then centrifuged $\left(16,000 \mathrm{~g}\right.$ for $5 \mathrm{~min}$ at $\left.4{ }^{\circ} \mathrm{C}\right)$ and the resulting supernatant was collected. Solvents contained in the $0.3 \mathrm{ml}$ of supernatant were dried under a stream of nitrogen gas. A $0.1 \mathrm{ml}$ volume of chloroform was added to the residues, which were subsequently dissolved again. To isolate DAG from other lipid content, thin layer chromatography plates were used. The standard solution for DAG was spotted. After the isolation step, the silica gel was collected and transferred to a tube and $1 \mathrm{ml}$ of chloroform was added and mixed thoroughly. The mixture was then centrifuged $\left(16,000 \mathrm{~g}\right.$ for $5 \mathrm{~min}$ at $\left.4{ }^{\circ} \mathrm{C}\right)$ and the resulting supernatant collected. Solvents contained in the $1 \mathrm{ml}$ of supernatant were dried under a stream of nitrogen gas. A $30 \mu \mathrm{l}$ volume of 2-propanol was added to the residue, after which the residue was dissolved again. DAG concentrations in the 2-propanol solution were determined using TG kits (Wako Pure Chemical Industries, Ltd., Osaka, Japan).

\section{Assay for liver Oxidized DAG $(D A G-O(O) H)$}

The assay for DAG-O(O)H was performed as described (Toriumi et al. 2013). Lipids were extracted from liver tissues using 2-propanol containing 1-palmitoyl-3-arachidoylglycerol hydroxide as an internal standard, $20 \mathrm{mmol} / 1$ butylated hydroxytoluene and $200 \mathrm{mmol} / 1$ triphenylphosphine. Butylated hydroxyltoluene and triphenylphosphine were added to prevent artifactual oxidation during the analytical procedure and to reduce hydroperoxide to hydroxide, respectively. The extract was injected into an octadecylsilyl column, and the fraction containing DAG-O $(\mathrm{O}) \mathrm{H}$ was collected. Methanol was used in the mobile phase. The fraction was then subsequently injected into a silica column and hexane/2-propanol used in the mobile phase to collect the fraction containing DAG-O $(\mathrm{O}) \mathrm{H}$. DAG-O $(\mathrm{O}) \mathrm{H}$ was subsequently labeled with pyrene-1-carbonyl cyanide in the presence of quinuclidine, and the labeled DAG-O $(\mathrm{O}) \mathrm{H}$ was detected by reversed phase HPLC coupled with fluorescence detection (excitation at $330 \mathrm{~nm}$ and emission at $405 \mathrm{~nm}$ ). Various DAG-O(O)H species with different acyl chains were eluted between 35 and $43 \mathrm{~min}$.

\section{Tissue sampling and histopathology}

Necropsy was performed at 16, 20 and 24 weeks of age as mentioned in section of Animals. At 16 weeks of age, 5 SDT fatty-Cho were tested. At 20 weeks of age, 6 SDT fatty-Cho were tested. At 24 weeks of age, 6 SDT fatty-Cho, 5 SDT fatty-NC, 5 SD-Cho, and 5 SD-NC were tested. The livers were immediately sampled and fixed in $10 \%$ neural-buffered formalin. After resection, the tissue was paraffin-embedded using standard techniques and thin-sectioned ( 3 to $5 \mu \mathrm{m}$ ). The sections were stained with hematoxylin and eosin (HE) and Sirius Red. These samples were all examined histopathologically in a blinded manner and findings were graded from normal (-) to severe (3+).

\section{$m R N A$ quantification with real-time quantitative $P C R$}

Total RNA was extracted from the livers of animals at 24 weeks of age. RNA was transcribed into cDNA using high capacity cDNA reverse transcription kits with RNA inhibitors (Applied Biosystems, Foster City, CA, USA). The reaction mixture was incubated for $10 \mathrm{~min}$ at $25^{\circ} \mathrm{C}, 2 \mathrm{~h}$ at $37^{\circ} \mathrm{C}$, and $5 \mathrm{~s}$ at $85^{\circ} \mathrm{C}$. Real time PCR quantification was performed in a $20 \mu$ reaction mixture with an automated sequence detector combined with StepOne plus (Applied Biosystems, Foster City, CA, USA). The reaction mixture made using TaqMan Gene Expression Master Mix (Applied Biosystems, Foster City, CA, USA) contained approximately $50 \mathrm{ng}$ of synthesized cDNA, $0.9 \mu \mathrm{mol} / 1$ primers, $0.25 \mu \mathrm{mol} / 1$ probes or TaqMan gene expression assays on demand and Universal Maser Mix (primer/probe set). The reaction mixture was incubated for $2 \mathrm{~min}$ at $50^{\circ} \mathrm{C}, 10 \mathrm{~min}$ at $95^{\circ} \mathrm{C}$, followed by 40 cycles of $15 \mathrm{~s}$ at $95^{\circ} \mathrm{C}$ and $60 \mathrm{~s}$ at $60{ }^{\circ} \mathrm{C}$. The following primers and FAM-conjugated probes were designed using Primer Express software (Applied Biosystems, Foster City, CA, USA): fatty acid 
synthase (FAS) (forward, ACTGAACGGCATTAC TCGGTCC; reverse, GTGTCCCATGTTGGATTTG GTG; probe, TTCCGCCAGAGCCCTTTGTTAAT TGG), acetyl-CoA Carboxylase (ACC) (forward, GCAGCTATGTTCAGAGAGTTCACC; reverse, CCA CCTCACAGTTGACTTGTTTTC; probe, CGGCGA CTTACGTTCCTAGTTGCACAAAA). The following gene expression was confirmed using TaqMan gene expression assays on demand and the Universal Maser Mix (primer/probe set): beta-actin (purchased from Applied Biosystems, Foster City, CA, USA), alpha smooth muscle actin ( $\alpha$-SMA) (Rn01759928_g1), monocyte chemoattractant protein-1 (MCP-1) (Rn00580555_m1), sterol regulatory element-binding protein-1 (SREBP-1) (Rn01495769_m1), microsomal triglyceride transfer protein (MTP) (Rn01522970_m1), transforming growth factor-beta (TGF- $\beta$ ) (Rn99999016_m1), tumor necrosis factor-alpha (TNF- $\alpha$ ) (Rn99999017_m1), and collagen type 1 (Rn01463848_m1).

\section{Statistical analysis}

Data are expressed as means \pm standard deviations. Statistical analysis for comparing 2 groups was performed using an F-test, followed by Student's t-test or Aspin-Welch's t-test. And statistical analysis for comparing 4 groups was performed using Bartlett's test, followed by Tukey-Kramer or Steel-Dwass test. Differences were considered significant at $\mathrm{p}<0.05$.

\section{Results}

Both groups of SDT fatty rats fed either with normal chow or $2 \%$ cholesterol presented with obesity, and there were no significant differences between the two groups. Obesity was sustained in both groups until 24 weeks of age (Fig. 1A). Plasma glucose level was higher in SDT fatty-Cho than in SDT fatty-NC at 16 weeks of age (Fig. 1B). Plasma TG level was lower in SDT fatty-Cho than in SDT fatty-NC at 16, 20 and 24 weeks of age (Fig. 1C). Plasma TC level was significantly higher in SDT fatty-Cho than in SDT fatty-NC throughout the observation period (Fig. 1D). There were no significant differences between the two groups of SDT fatty rats in plasma ALT and AST activities until 24 weeks of age (Figs 1E and 1F). Plasma insulin levels in both groups of SDT fatty rats showed similar patterns until 24 weeks of age (Fig. 1G).

Plasma free choline level was significantly higher in SDT fatty-Cho than in SDT fatty-NC at 10 and 24 weeks of age (Fig. 1H).
Relative liver weight was significantly heavier in SDT fatty-Cho than in SDT fatty-NC (Fig. 2A). Hepatic TG content in SDT fatty-Cho tended to increase, and the content mean value was over two times higher in SDT fatty-Cho than in SDT fatty-NC (SDT fatty-NC, $53.6 \mathrm{mg} / \mathrm{g}$ tissue vs. SDT fatty-Cho, $126.4 \mathrm{mg} / \mathrm{g}$ tissue), although this increase was not significant (Fig. 2B). Hepatic FFA and TC content were significantly higher in SDT fatty-Cho than in SDT fatty-NC (Figs 2C and 2D). Hepatic FC content tended to be higher in SDT fatty-Cho than in SDT fatty-NC (mean value: SDT fatty-NC, $3.62 \mathrm{mg} / \mathrm{g}$ tissue vs. SDT fatty-Cho, $5.25 \mathrm{mg} / \mathrm{g}$ tissue), although this increase was not significant (Fig. 2E). Hepatic DAG level was significantly higher in SDT fatty-Cho than in SDT fatty-NC at 24 weeks of age (Fig. 2F). Furthermore, hepatic DAG-O(O)H level in SDT fatty-Cho tended to increase, and the mean value was over two times higher in SDT fatty-Cho than in SDT fatty-NC (SDT fatty-NC, $101.3 \mathrm{nmol} / \mathrm{g}$ tissue vs. SDT fatty-Cho, $214.0 \mathrm{nmol} / \mathrm{g}$ tissue), although this increase was not significant (Fig. 2G).

Liver histopathology was examined by HE staining (Figs 3A-3D). Histopathologically, severe changes $(3+)$ in the liver, including fatty and vacuolar changes, were observed in SDT fatty-Cho from 16 weeks of age. Moderate changes (2+) of hypertrophy and very slight or slight changes of inflammation were also observed in SDT fatty-Cho from 16 weeks of age. Hepatic fibrosis was also confirmed by Sirius Red staining (Figs 3E-3H). There are no apparent changes on SD-NC and SD-Cho at 24 weeks of age. Slight changes $(+)$ indicating fibrosis were observed in SDT fatty-Cho from 16 weeks of age; however, these changes were not observed in SDT fatty-NC at 24 weeks of age (Table 1). There are no apparent changes on SD-NC and SD-Cho at 24 weeks of age.

At 24 weeks of age, there were no significant differences between SDT fatty-Cho and SDT fatty-NC in terms of mRNA expression of lipogenic genes, such as SREBP-1, FAS, ACC, (Figs 4A-4C) and fibrotic genes, such as $\alpha$-SMA (Fig. 4H). MTP mRNA levels, which are related to the secretion of very low-density lipoproteins (VLDL), were significantly lower in SDT fatty-Cho than in SDT fatty-NC (Fig. 4D). Inflammatory genes, including TNF- $\alpha$, and MCP-1, were significantly higher in SDT fatty-Cho than in SDT fatty-NC (Figs 4E and 4F). The mRNA levels of fibrotic gene Collagen type 1 and TGF- $\beta$ tended to be higher in SDT fatty-Cho than in SDT fatty-NC, although the increase was not significant (Figs $4 \mathrm{G}$ and $4 \mathrm{I})$. 

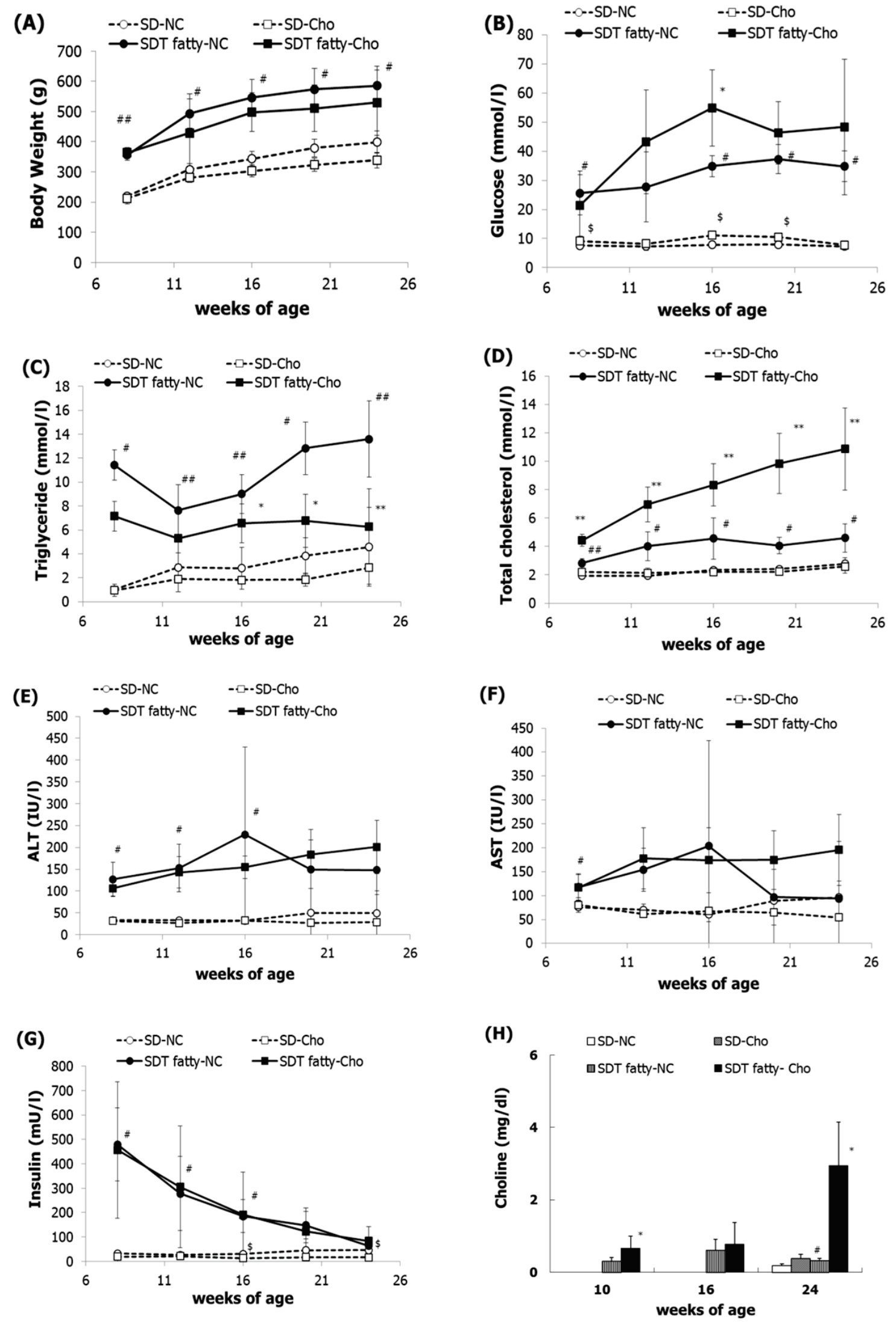

Fig. 1. Effects of cholesterol feeding on body weight and biological parameters in SDT fatty rats and SD rats. A, Body weight; B, Glucose; C, Triglyceride; D, Total cholesterol; E, Alanine aminotransferase (ALT); F, Aspartate aminotransferase (AST); G, Insulin; $\mathbf{H}$, Choline in SDT fatty rats and SD rats. Data shown as means \pm standard deviations $(n=5-17) . * * p<0.01, * p<0.05$; significant difference between SDT fatty rats fed $2 \%$ cholesterol (Cho) and SDT fatty rats fed normal chow (NC). \#\# $p<0.01, \# p<0.05$, significant difference between SDT fatty rats fed NC and SD rats fed NC; $\$ p<0.05$, significant difference between SD rats fed Cho and SD rats fed NC. 

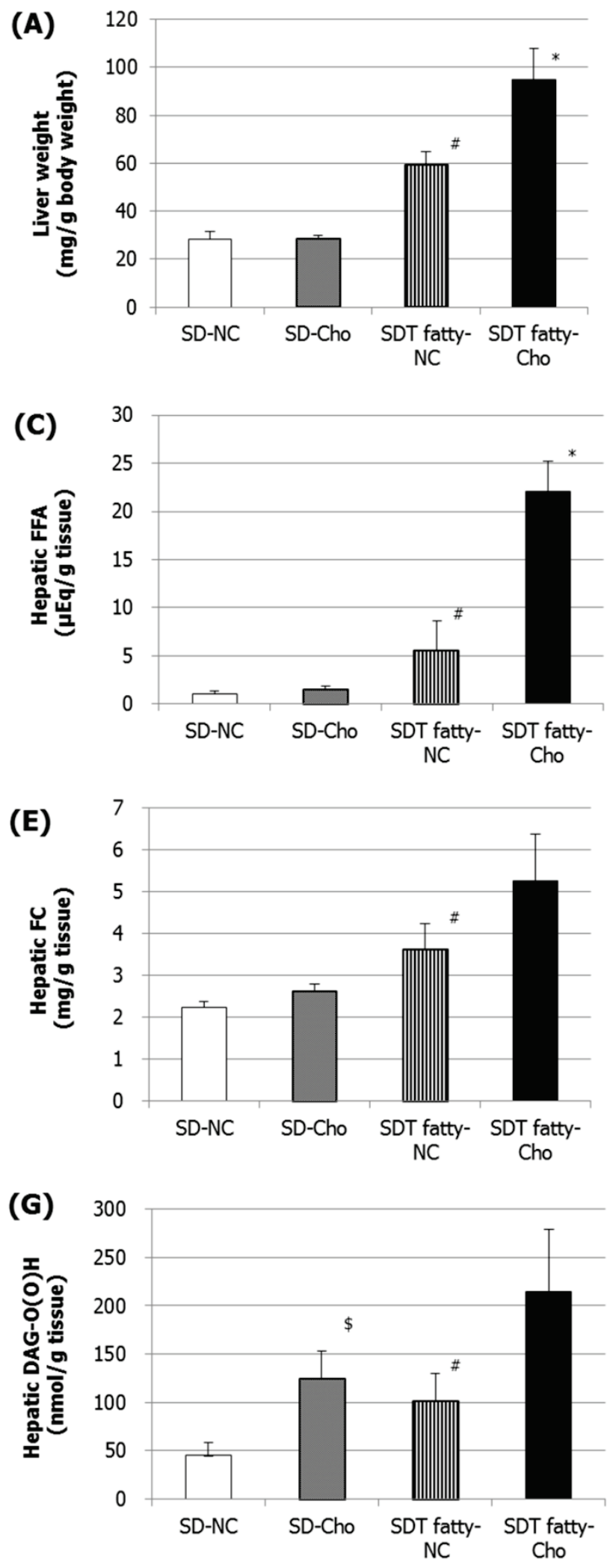
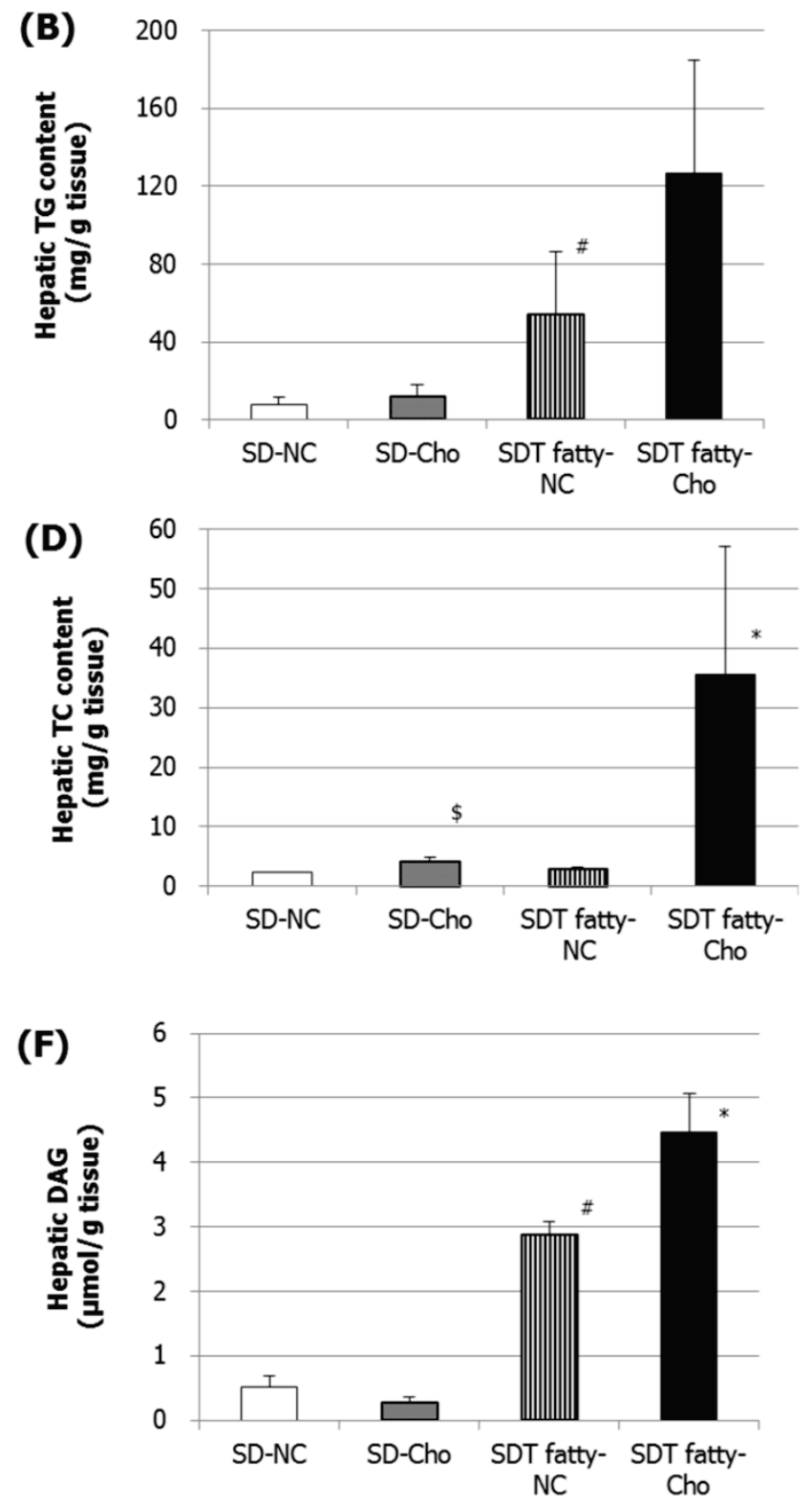

Fig. 2. Effects of cholesterol feeding on liver weight and hepatic lipid content. A, liver weight; $\mathbf{B}$, hepatic triglyceride (TG) content; C, hepatic free fatty acid (FFA) content; D, hepatic total cholesterol (TC) content; $\mathbf{E}$, hepatic free cholesterol (FC) content; $\mathbf{F}$, hepatic diacylglycerol (DAG) content; G, hepatic oxidized DAG (DAG-O(O)H) in SDT fatty rats and SD rats at 24 weeks of age. Data shown as means \pm standard deviations $(n=5-6)$ * $p<0.05$, significant difference between SDT fatty rats fed $2 \%$ cholesterol (Cho) and SDT fatty rats fed normal chow (NC); \# p<0.05, significant difference between SDT fatty rats fed NC and SD rats fed NC; $\$ p<0.05$, significant difference between SD rats fed Cho and SD rats fed NC. 
A

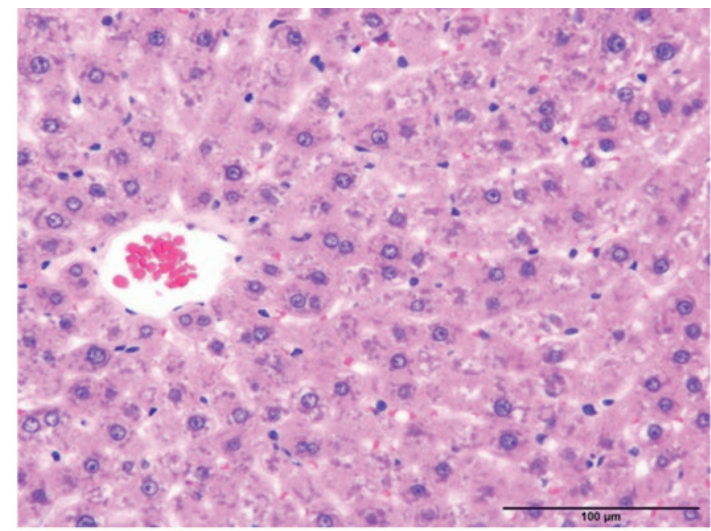

$\mathrm{B}$

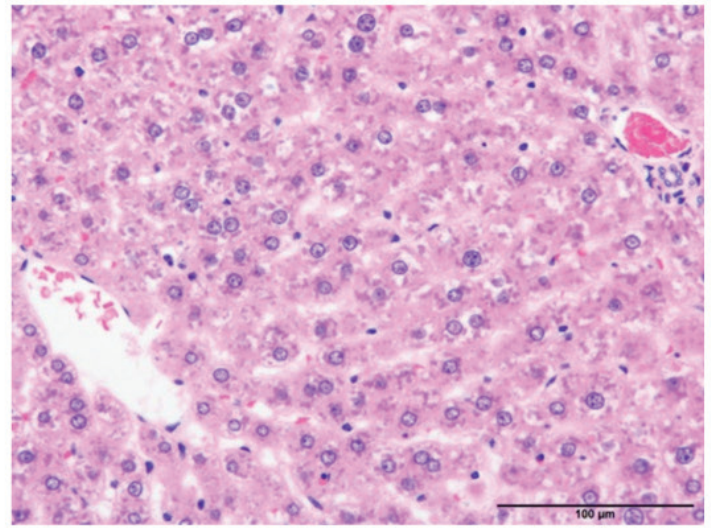

C

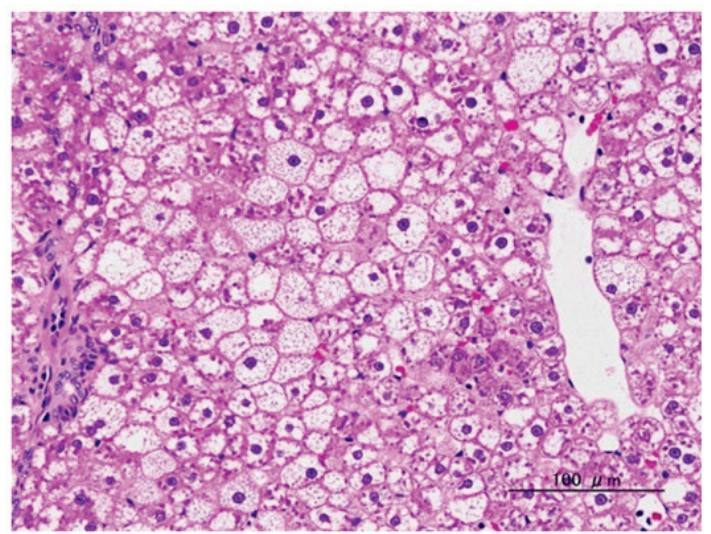

$\mathrm{D}$

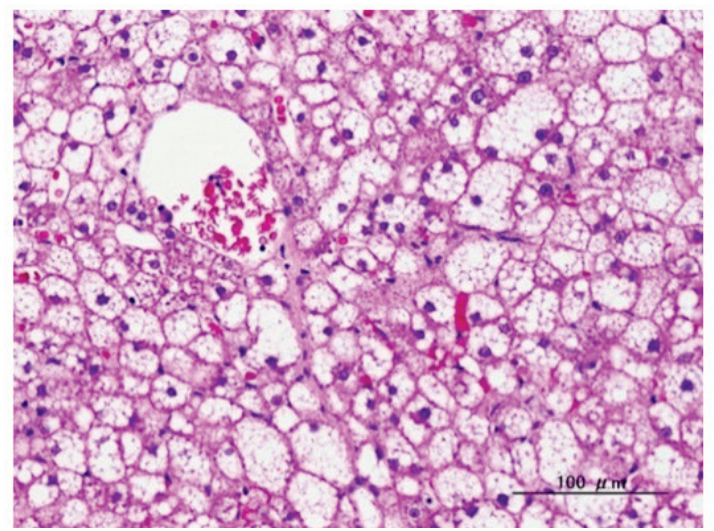

$\mathrm{E}$

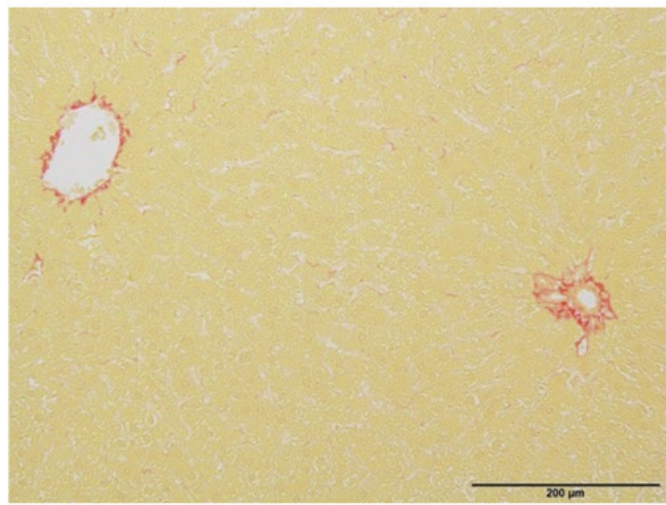

$\mathrm{F}$

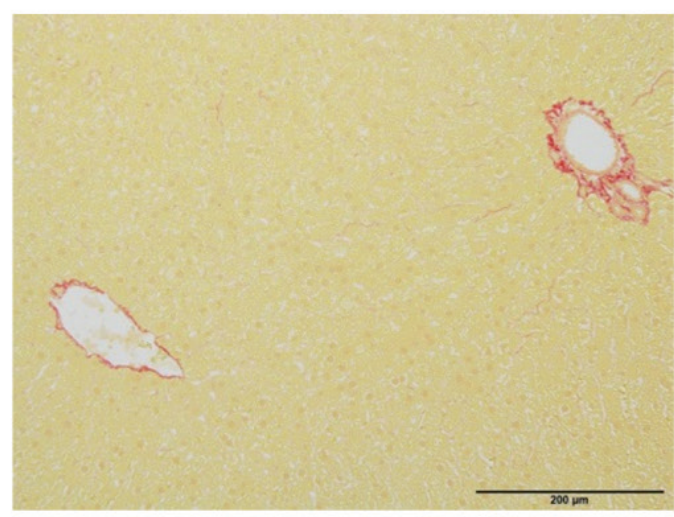

G

$\mathrm{H}$
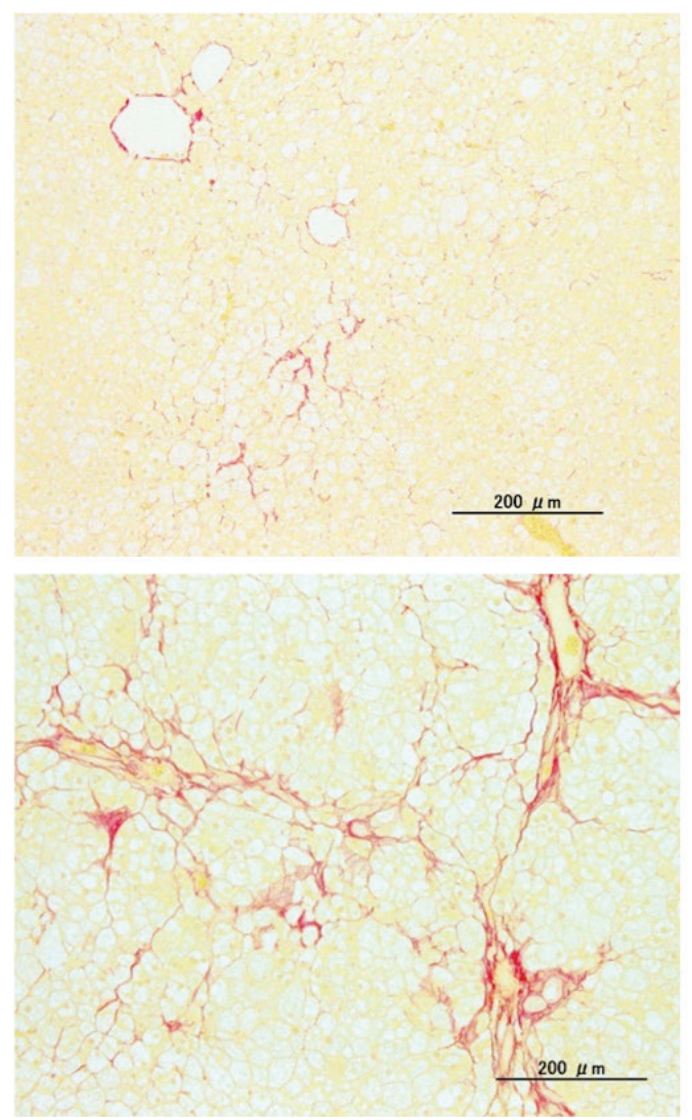

Fig. 3. Liver histopathology. Hematoxylin and eosin (HE) staining (A, SD rats fed normal chow (NC); B, SD rats fed $2 \%$ cholesterol (Cho); C, SDT fatty rats fed NC; D, SDT fatty rats fed Cho) and Sirius red (E, SD rats fed NC; F, SD rats fed Cho; $\mathbf{G}$, SDT fatty rats fed NC; H, SDT fatty rats fed Cho) at 24 weeks of age. The scale bar is $100 \mu \mathrm{m}$ for HE staining and $200 \mu \mathrm{m}$ for Sirius red staining. 
(A)

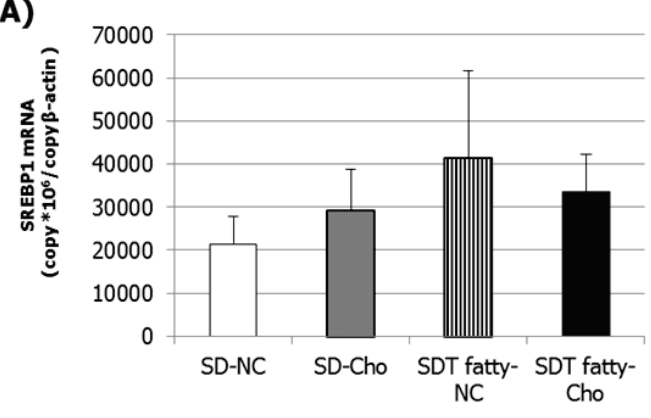

(C)

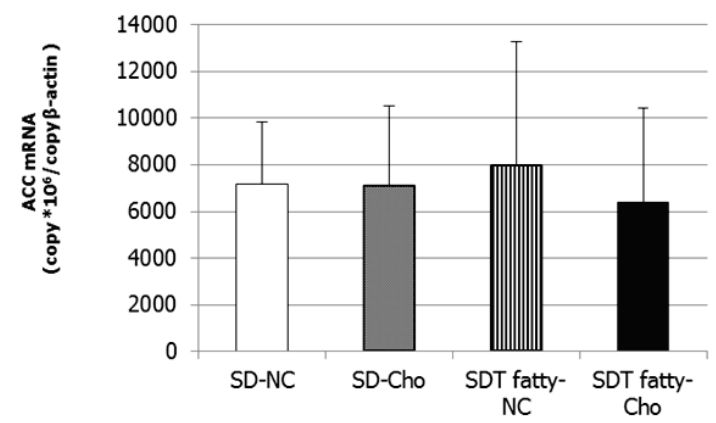

(E)
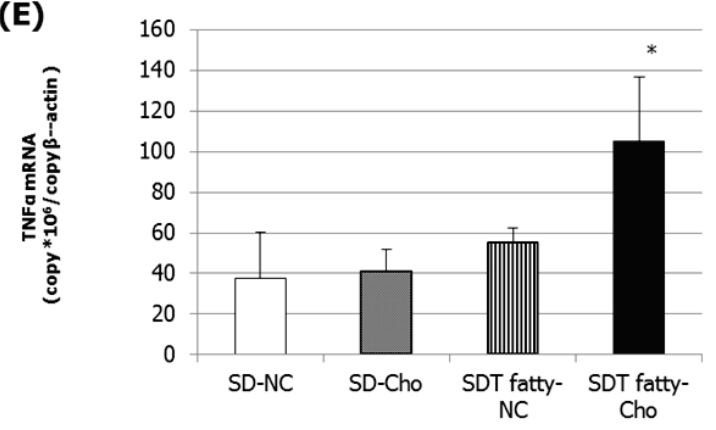

(G)

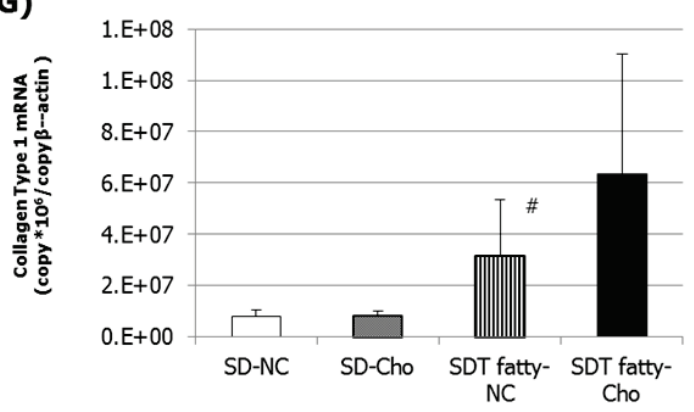

(I)

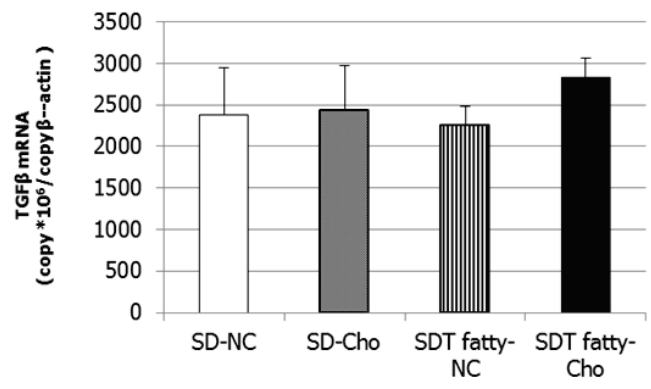

(B)

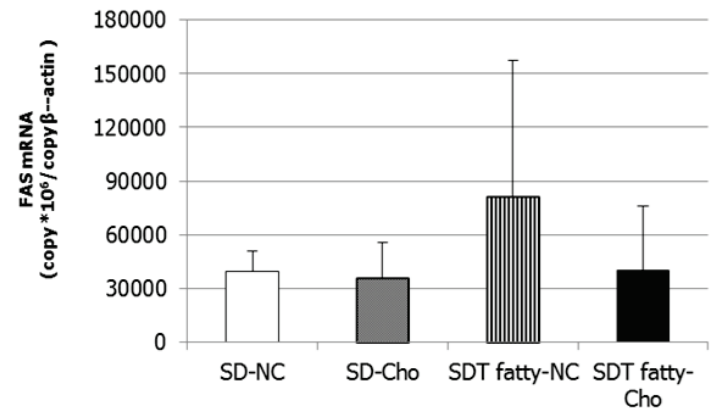

(D)

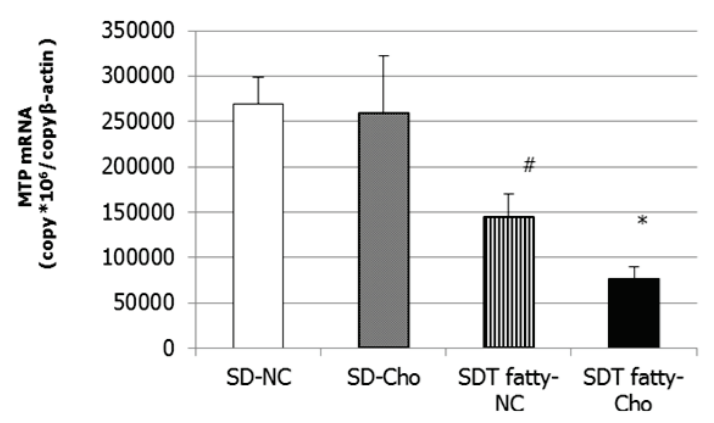

(F)

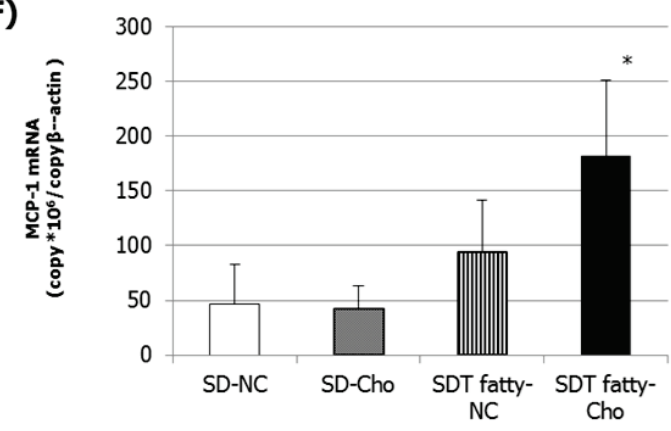

(H)

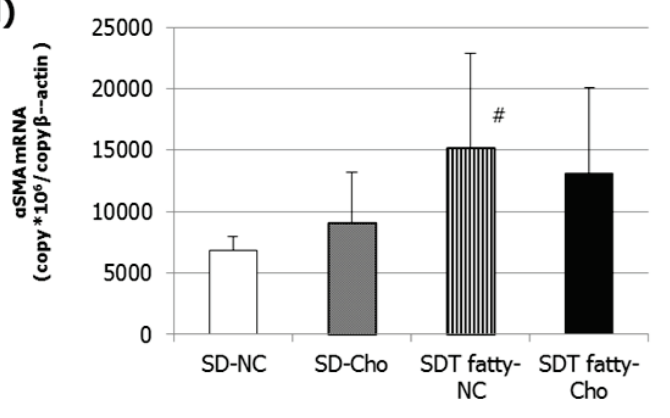

Fig. 4. Expression of genes related to triglyceride synthesis and secretion, inflammation and fibrosis. A, Sterol regulatory elementbinding protein (SREBP)-1; B, Fatty acid synthase (FAS); C, Acetyl-CoA carboxylase (ACC); D, Microsomal triglyceride transfer protein (MTP); E, Tumor necrosis factor (TNF)-a; F, Monocyte chemoattractant protein (MCP)-1; G, Collagen Type 1; $\mathbf{H}$, a-smooth muscle actin (SMA); I, Transforming growth factor (TGF)- $\beta$ in SDT fatty rats and SD rats at 24 weeks of age. Data shown as means \pm standard deviations $(n=5-6)$. * $p<0.05$, significant difference between SDT fatty rats fed $2 \%$ cholesterol (Cho) and SDT fatty rats fed normal chow (NC), \# $\mathrm{p}<0.05$, significant difference between SDT fatty rats fed NC and SD rats fed NC. 
Table 1. Histopathological findings in livers of SDT fatty rats and SD rats.

\begin{tabular}{|c|c|c|c|c|c|c|c|}
\hline Weeks of age & & 16 weeks & 20 weeks & 24 weeks & 24 weeks & 24 weeks & 24 weeks \\
\hline Strain & & SDT fatty & SDT fatty & SDT fatty & SD & SDT fatty & SD \\
\hline Diet & & \multicolumn{4}{|c|}{ CRF-1 added $2 \%$ cholesterol } & \multicolumn{2}{|c|}{ CRF-1 } \\
\hline Hepatosteatosis & - & 0 & 0 & 0 & 5 & 0 & 5 \\
\hline \multirow{4}{*}{ (Vacuolation/Fatty change) } & \pm & 0 & 0 & 0 & 0 & 1 & 0 \\
\hline & + & 0 & 0 & 0 & 0 & 0 & 0 \\
\hline & $2+$ & 1 & 1 & 1 & 0 & 4 & 0 \\
\hline & $3+$ & 4 & 5 & 5 & 0 & 0 & 0 \\
\hline Hypertrophy of hepatocyte & - & 0 & 0 & 0 & 5 & 0 & 5 \\
\hline \multirow[t]{4}{*}{ (with Vacuolation/Fatty change) } & \pm & 1 & 0 & 0 & 0 & 1 & 0 \\
\hline & + & 1 & 0 & 0 & 0 & 0 & 0 \\
\hline & $2+$ & 3 & 1 & 1 & 0 & 4 & 0 \\
\hline & $3+$ & 0 & 5 & 5 & 0 & 0 & 0 \\
\hline \multirow[t]{5}{*}{ Fibrosis } & - & 1 & 0 & 0 & 5 & 0 & 5 \\
\hline & \pm & 3 & 4 & 2 & 0 & 5 & 0 \\
\hline & + & 1 & 2 & 4 & 0 & 0 & 0 \\
\hline & $2+$ & 0 & 0 & 0 & 0 & 0 & 0 \\
\hline & $3+$ & 0 & 0 & 0 & 0 & 0 & 0 \\
\hline \multirow[t]{5}{*}{ Infiltration, inflammatory cells } & - & 2 & 4 & 4 & 5 & 3 & 5 \\
\hline & \pm & 2 & 1 & 2 & 0 & 2 & 0 \\
\hline & + & 1 & 1 & 0 & 0 & 0 & 0 \\
\hline & $2+$ & 0 & 0 & 0 & 0 & 0 & 0 \\
\hline & $3+$ & 0 & 0 & 0 & 0 & 0 & 0 \\
\hline
\end{tabular}

-, negative; \pm , very slight; +, slight; $2+$, moderate; $3+$, severe.

\section{Discussion}

In the previous study, female SDT fatty rats spontaneously present with features of NASH at 32-40 weeks of age (Ishii et al. 2015). In the present study, to accelerate the onset of NASH in female SDT fatty rats, we investigated the pathophysiological features of livers from female SDT fatty rats fed cholesterolenriched chow in comparison with female SDT fatty rats fed normal chow.

SDT fatty-Cho showed significantly higher liver mRNA expression of MCP-1 and TNF- $\alpha$, suggesting that SDT fatty-Cho accelerated liver injury and inflammation. Furthermore, SDT fatty-Cho showed increases in liver mRNA expression related with fibrosis, including Collagen type 1 and TGF- $\beta$. In histopathology examinations, hepatic fibrosis was observed in SDT fatty-Cho at 16 weeks of age. The same phenomenon was observed in SDT fatty-NC from 32 weeks of age (Ishii et al. 2015). Blood glucose levels in SDT fatty-Cho tended to increase as compared with those in SDT fatty-NC. Their ability to change glucose to fatty acid may be disrupted by excess lipid accumulation in their liver. In accordance with that, liver FAS, ACC, SREBP1 mRNA expression tended to be lower in SDT fatty-Cho than SDT fatty-NC. The onset of NASH in SDT fatty rats appears to be accelerated by feeding cholesterol-enriched chow. At 24 weeks of age, SDT fatty-Cho obviously showed fibrosis. However, fibrosis was not obviously observed in SDT fatty-NC at 24 weeks of age. There were clear differences for fibrosis onset between SDT fatty-Cho and SDT fatty-NC at 24 weeks of age. The both group animals at 24 weeks of age were the best for making a comparison to investigate the mechanism of NASH onset acceleration. The expression of genes related to the secretion of VLDL, MTP, decreased in SDT fatty-Cho. Moreover, FFA TG, DAG, TC and FC in the liver increased in SDT fatty-Cho. These phenotypes may be caused by the impairment of VLDL secretion and dietary intake of abundant cholesterol. In this study, ballooning degeneration of hepatocytes in SDT fatty-Cho was not observed until 24 weeks of age. In further study for the longer period, it is necessary to confirm that the ballooning degeneration will be seen in this model. 
At 24 weeks of age, SDT fatty-Cho presented with features that are considered likely to affect the onset of NASH. First, excess FFA could contribute to the activation of mixed lineage kinase 3 , which can activate c-Jun N-terminal kinase (JNK) (Jaeschke and Davis 2007, Ibrahim et al. 2014). JNK activation is pivotal in the development of NASH. This activation contributes to the production of inflammatory cytokines, including TNF- $\alpha$ and MCP-1 (Farrell et al. 2012). Second, hepatic DAG and DAG-O(O)H levels were elevated by feeding cholesterol-enriched chow. Through this change, protein kinase $\mathrm{C}$ is activated, thus resulting in severe inflammation (Takekoshi et al. 1995, Toriumi et al. 2013). In actuality, the inflammatory genes, TNF- $\alpha$ and MCP-1, significantly increased in SDT fatty-Cho at 24 weeks of age. Furthermore, hepatic FC increased in SDT fatty-Cho. Hepatic FC may be involved in the development of hepatic fibrosis in SDT fatty-Cho. Hepatic FC accumulation reportedly causes changes to the sensitivity of hepatic stellate cells for TGF- $\beta$ through Toll-like receptor 4 (TLR4). FC accumulation in hepatic stellate cells is also important for NASH fibrosis (Teratani et al. 2012, Tomita et al. 2014).

Several studies have shown that dietary cholesterol intake is related to NASH onset in animal models (Tous et al. 2006, Wouters et al. 2008). These findings imply that dietary cholesterol intake may be an important factor for the development of NASH. Excess FFA could also activate hepatic stellate cells, thus resulting in the development of fibrosis (Bechmann et al. 2009, Li et al. 2016). Result from excess FFA and FC accumulation, the fibrotic genes, TGF- $\beta$ and Collagen type 1 , increased in SDT fatty-Cho. We think the fibrogenesis in the liver of SDT fatty-Cho were accelerated by not only intrahepatic inflammation induced by hepatic lipid but also intrahepatic FFA and FC accumulation.

To diagnose NASH, liver biopsies are required. As expected, liver biopsies are invasive. Numerous studies to find non-invasive biomarkers or scoring systems for NASH are ongoing. In general, AST and ALT are assessed in simple steatosis or NASH patients. However, these individual markers are not useful in diagnosing NASH. Also, in this study, plasma AST and ALT activities in SDT fatty-Cho were comparable with those in SDT fatty-NC. Choline is used for phosphatidylcholine biosynthesis. Phosphatidylcholine is important for VLDL output. SDT fatty-Cho presented with increased plasma choline concentration similar to human NASH patients. Plasma choline concentrations in
NASH patients are higher than in simple steatosis patients and healthy controls (Imajo et al. 2012). On the other hand, treatment with choline in combination of docosahexaenoic acid and vitamin E reportedly decreased the NASH in children and adolescent (Zöhrer et al. 2017). And association between plasma choline concentrations and expression of MTP showed a negative correlation in patients with NAFLD (Imajo et al. 2012). The expression of genes related to the secretion of VLDL, MTP, decreased in SDT fatty-Cho. We think that elevated levels of serum choline were result from liver dysfunction caused by excess of cholesterol loading, not causal factor of liver dysfunction. The increased plasma choline concentration is considered to be induced by a suppression of choline uptake to the liver and/or an increase of choline release from the liver. Liver choline deficiency may occur in SDT fatty-Cho similar to choline deficient diets models. In liver choline deficiency, SDT fatty-Cho could not output VLDL from their liver like choline deficient diets models. The relationship between plasma choline concentration and expression of MTP which confirmed in SDT fatty-Cho showed the similarity of this model to human NASH.

In conclusion, SDT fatty rats fed cholesterolenriched chow presented with NASH-like hepatic lesions at 16 weeks of age. The hepatic fibrosis was observed starting from 16 weeks of age, and obviously showed hepatic fibrosis at 24 weeks of age. There were no significant changes in the effects of feeding a cholesterolenriched diet in SD rats. From these results, cholesterolenriched chow was shown to be able to accelerate the onset of NASH in SDT fatty rats. The most important contributing factors for the development of NASH in humans remain unknown. However, SDT fatty rats fed cholesterol-enriched chow have the potential to become a valuable animal model for NASH associated with type 2 diabetes and obesity, for which few models currently exist.

\section{Conflict of Interest}

Toriniwa, Muramatsu, Ishii and Ohta are employees of Japan Tobacco Inc.

\section{Acknowledgements}

We wish to thank Mr. Nobuhiro Inaba and Mr. Naruhisa Ryumon (JT Creative Service) for their support with long-term animal care, and CLEA Japan and Skylight Biotech for their support with measurements of blood choline levels. 


\section{References}

BECHMANN LP, ZAHN D, GIESELER RK, FINGAS CD, MARQUITAN G, JOCHUM C, GERKEN G, FRIEDMAN SL, CANBAY A: Resveratrol amplifies profibrogenic effects of free fatty acids on human hepatic stellate cells. Hepatol Res 39: 601-608, 2009.

DE ALWIS NM, DAY CP: Non-alcoholic fatty liver disease: the mist gradually clears. $J$ Hepatol 48 (Suppl 1): S104-S112, 2008.

DIEHL AM: Lessons from animal models of NASH. Hepatol Res 33: 138-144, 2005.

ERTLE J, DECHENE A, SOWA JP, PENNDORF V, HERZER K, KAISER G, SCHLAAK JF, GERKEN G, SYN WK, CANBAY A: Non-alcoholic fatty liver disease progresses to hepatocellular carcinoma in the absence of apparent cirrhosis. Int J Cancer 128: 2436-2443, 2011.

FARRELL GC, VAN ROOYEN D, GAN L, CHITTURI S: NASH is an inflammatory disorder: pathogenic, prognostic and therapeutic implications. Gut Liver 6: 149-171, 2012.

GE F, ZHOU S, HU C, LOBDELL HT, BERK PD: Insulin- and leptin-regulated fatty acid uptake plays a key causal role in hepatic steatosis in mice with intact leptin signaling but not in ob/ob or db/db mice. Am J Physiol Gastrointest Liver Physiol 299: G855-G866, 2010.

GREENFIELD V, CHEUNG O, SANYAL AJ: Recent advances in nonalcholic fatty liver disease. Curr Opin Gastroenterol 24: 320-327, 2008.

HUCKE F, SIEGHART W, SCHONIGER-HEKELE M, PECK-RADOSAVLJEVIC M, MULLER C: Clinical characteristics of patients with hepatocellular carcinoma in Austria - is there a need for a structured screening program? Wien Klin Wochenschr 123: 542-551, 2011.

IBRAHIM SH, GORES GJ, HIRSOVA P, KIRBY M, MILES L, JAESCHKE A, KOHLI R: Mixed lineage kinase 3 deficient mice are protected against the high fat high carbohydrate diet-induced steatohepatitis. Liver Int 34: 427-437, 2014.

IMAJO K, FUJITA K, YONEDA M, SHINOHARA Y, SUZUKI K, MAWATARI H, TAKAHASHI J, NOZAKI Y, SUMIDA Y, KIRIKOSHI H, SAITO S, NAKAMUTA M, MATSUHASHI N, WADA K, NAKAJIMA A: Plasma free choline is a novel non-invasive biomarker for early-stage non-alcoholic steatohepatitis: a multicenter validation study. Hepatol Res 42: 757-766, 2012.

IMAJO K, YONEDA M, FUJITA K, KESSOKU T, TOMENO W, OGAWA Y, SHINOHARA Y, SEKINO Y, MAWATARI H, NOZAKI Y, KIRIKOSHI H, TAGURI M, TOSHIMA G, TAKAHASHI J, SAITO S, WADA K, NAKAJIMA A: Oral choline tolerance test as a novel noninvasive method for predicting nonalcoholic steatohepatitis. J Gastroenterol 49: 295-304, 2014.

ISHII Y, MOTOHASHI Y, MURAMATSU M, KATSUDA Y, MIYAJIMA K, SASASE T, YAMADA T, MATSUI T, KUME S, OHTA T: Female spontaneously diabetic Torii fatty rats develop nonalcoholic steatohepatitis-like hepatic lesions. World J Gastroenterol 21: 9067-9078, 2015.

JAESCHKE A, DAVIS RJ: Metabolic stress signaling mediated by mixed-lineage kinases. Mol Cell 27: 498-508, 2007.

KATSUDA Y, OHTA T, MIYAJIMA K, KEMMOCHI Y, SASASE T, TONG B, SHINOHARA M, YAMADA T: Diabetic complications in obese type 2 diabetic rat models. Exp Anim 63: 121-132, 2014.

KAWARATANI H, TSUJIMOTO T, KITAZAWA T, KITADE M, YOSHIJI H, UEMURA M, FUKUI H: Innate immune reactivity of the liver in rats fed a choline-deficient L-amino-acid-defined diet. World J Gastroenterol 14: 6655-6661, 2008.

LI BH, HE FP, YANG X, CHEN YW, FAN JG: Steatosis induced CCL5 contributes to early-stage liver fibrosis in nonalcoholic fatty liver disease progress. Transl Res 180: 103-117, 2016.

MALIK SM, GUPTE PA, DE VERA ME, AHMAD J: Liver transplantation in patients with nonalcoholic steatohepatitis-related hepatocellular carcinoma. Clin Gastroenterol Hepatol 7: 800-806, 2009.

MARI M, CABALLERO F, COLELL A, MORALES A, CABALLERIA J, FERNANDEZ A, ENRICH C, FERNANDEZ-CHECA JC, GARCIA-RUIZ C: Mitochondrial free cholesterol loading sensitizes to TNF- and Fas-mediated steatohepatitis. Cell Metab 4: 185-198, 2006. 
MASUYAMA T, KATSUDA Y, SHINOHARA M: A novel model of obesity-related diabetes: introgression of the Lepr(fa) allele of the Zucker fatty rat into nonobese Spontaneously Diabetic Torii (SDT) rats. Exp Anim 54: $13-20,2005$.

OHTA T, KATSUDA Y, MIYAJIMA K, SASASE T, KIMURA S, TONG B, YAMADA T: Gender differences in metabolic disorders and related diseases in Spontaneously Diabetic Torii-Lepr(fa) rats. J Diabetes Res 2014: 841957, 2014.

TAKEKOSHI S, KAMBAYASHI Y, NAGATA H, TAKAGI T, YAMAMOTO Y, WATANABE K: Activation of protein kinase C by oxidized diacylglycerols. Biochem Biophys Res Commun 217: 654-660, 1995.

TERATANI T, TOMITA K, SUZUKI T, OSHIKAWA T, YOKOYAMA H, SHIMAMURA K, TOMINAGA S, HIROI S, IRIE R, OKADA Y, KURIHARA C, EBINUMA H, SAITO H, HOKARI R, SUGIYAMA K, KANAI T, MIURA S, HIBI T: A high-cholesterol diet exacerbates liver fibrosis in mice via accumulation of free cholesterol in hepatic stellate cells. Gastroenterology 142: 152-164, e1-e10, 2012.

TOMITA K, TERATANI T, SUZUKI T, SHIMIZU M, SATO H, NARIMATSU K, USUI S, FURUHASHI H, KIMURA A, NISHIYAMA K, MAEJIMA T, OKADA Y, KURIHARA C, SHIMAMURA K, EBINUMA H, SAITO H, YOKOYAMA H, WATANABE C, KOMOTO S, NAGAO S, SUGIYAMA K, AOSASA S, HATSUSE K, YAMAMOTO J, HIBI T, MIURA S, HOKARI R, KANAI T: Acyl-CoA:cholesterol acyltransferase 1 mediates liver fibrosis by regulating free cholesterol accumulation in hepatic stellate cells. J Hepatol 61: 98-106, 2014.

TORIUMI K, HORIKOSHI Y, YOSHIYUKI OSAMURA R, YAMAMOTO Y, NAKAMURA N, TAKEKOSHI S: Carbon tetrachloride-induced hepatic injury through formation of oxidized diacylglycerol and activation of the PKC/NF-kappaB pathway. Lab Invest 93: 218-229, 2013.

TOUS M, FERRE N, RULL A, MARSILLACH J, COLL B, ALONSO-VILLAVERDE C, CAMPS J, JOVEN J: Dietary cholesterol and differential monocyte chemoattractant protein-1 gene expression in aorta and liver of apo E-deficient mice. Biochem Biophys Res Commun 340: 1078-1084, 2006.

TSUJIMOTO T, KAWARATANI H, KITAZAWA T, HIRAI T, OHISHI H, KITADE M, YOSHIJI H, UEMURA M, FUKUI H: Decreased phagocytic activity of Kupffer cells in a rat nonalcoholic steatohepatitis model. World $J$ Gastroenterol 14: 6036-6043, 2008.

TSUJIMOTO T, KAWARATANI H, KITAZAWA T, YOSHIJI H, FUJIMOTO M, UEMURA M, FUKUI H: Immunotherapy for nonalcoholic steatohepatitis using the multiple cytokine production modulator Y-40138. World J Gastroenterol 15: 5533-5540, 2009.

WOUTERS K, VAN GORP PJ, BIEGHS V, GIJBELS MJ, DUIMEL H, LUTJOHANN D, KERKSIEK A, VAN KRUCHTEN R, MAEDA N, STAELS B, VAN BILSEN M, SHIRI-SVERDLOV R, HOFKER MH: Dietary cholesterol, rather than liver steatosis, leads to hepatic inflammation in hyperlipidemic mouse models of nonalcoholic steatohepatitis. Hepatology 48: 474-486, 2008.

XU J, KULKARNI SR, DONEPUDI AC, MORE VR, SLITT AL: Enhanced Nrf2 activity worsens insulin resistance, impairs lipid accumulation in adipose tissue, and increases hepatic steatosis in leptin-deficient mice. Diabetes 61: 3208-3218, 2012.

YANG JD, KIM B, SANDERSON SO, ST SAUVER JL, YAWN BP, PEDERSEN RA, LARSON JJ, THERNEAU TM, ROBERTS LR, KIM WR: Hepatocellular carcinoma in Olmsted County, Minnesota, 1976-2008. Mayo Clin Proc 87: 9-16, 2012.

ZÖHRER E, ALISI A, JAHNEL J, MOSCA A, DELLA CORTE C, CRUDELE A, FAULER G, NOBILI V: Efficacy of docosahexaenoic acid-choline-vitamin E in paediatric NASH: a randomized controlled clinical trial. Appl Physiol Nutr Metab 42: 948-954, 2017. 